\title{
Parvovirose Congênita: Relato de Caso
}

\author{
Congenital Parvovirus Infection: case report
}

Daniela F. Gradia, Sebastião M. Zanforlin F. ${ }^{\circ}$, Thomaz R. Gollop

\section{RESUM0}

\begin{abstract}
Apresentamos um caso de regressão espontânea de hidropisia fetal provavelmente causada por infecção materno-fetal pelo parvovírus B19. Além de hidropisia, observamos anemia e hipocontratilidade cardíaca no feto. O diagnóstico foi estabelecido pela soma dos achados ultra-sonográficos, detecção do vírus no soro materno, hemograma fetal e dosagem de enzimas hepáticas fetais.
\end{abstract}

PALAVRAS-CHAVE: Viroses. Hidropisia fetal não imune. Infecções na gestação. Diagnóstico pré-natal.

\section{Introdução}

O parvovírus é um vírus DNA da família Parvoviridae responsável pelo eritema infeccioso ou quinta moléstia infecciosa. A infecção é comum na infância, devida principalmente à cepa B19. O trato respiratório é a principal via de transmissão. A infecção da criança ou adulto imunocompetente tem resolução rápida, sem maiores conseqüências. No entanto, a infecção durante a vida intra-uterina pode ser grave, merecendo atenção especial pelas alterações fetais que pode provocar como, por exemplo, quadros de anemia, hidropisia e até óbito fetal $^{2}$.

A incidência desta virose é maior durante a infância. Na idade adulta, encontra-se prevalência de imunidade entre $40 \%$ e $60 \%{ }^{8}$, índices que podem alcançar de $80 \%$ a $90 \%{ }^{6}$. Nesta idade, a incidência de infecção aguda está em torno de $1 \%$ e acreditase que a infecção de mulheres grávidas não ultrapasse a taxa observada para a população adulta $^{4}$.

Em estudo de 1990 da "Public Health

Instituto de Medicina Fetal e Genética Humana

Correspondência:

Rua Félix de Souza, 321 - CEP 04612-080 São Paulo SP

A/C: Prof. Dr. Thomaz R. Gollop

Trabalho parcialmente financiado pelo CNPq.
Laboratory Service Working Party on Fifth Disease" (Divisão de Trabalhos Sobre a Quinta Moléstia dos Serviços Laboratoriais de Saúde Pública da Inglaterra) $^{7}$ a transmissão viral, pela via placentária, foi estimada em 33\%, proporção que aumenta após a $20^{\mathrm{a}}$ semana. Estima-se que $9 \%$ dos casos de transmissão fetal resultem em acometimento do feto ${ }^{4}$.

\section{Relato de caso}

Uma mulher, gesta 3 para 1 , foi encaminhada ao Instituto de Medicina Fetal e Genética Humana para aconselhamento genético devido à idade materna avançada (41 anos). A paciente do grupo sangüíneo $\mathrm{A}$ Rh positivo, grávida de $181 / 2$ semanas, optou por realizar amniocentese em que se coletaram $20 \mathrm{ml}$ de líqüido. A análise citogenética revelou resultado normal (46 XY). Durante a monitoração ultra-sonográfica do exame, observou-se que o feto apresentava ascite. Recomendou-se à gestante a realização de Ultrasonografia Morfológica.

Com 19 1/2 semanas de gestação, a paciente submeteu-se ao exame recomendado. A ultrasonografia mostrou ascite evidente (Figura. 1), coração hipocontrátil, com área no limite superior da normalidade e derrame pericárdico (Figura 2). 


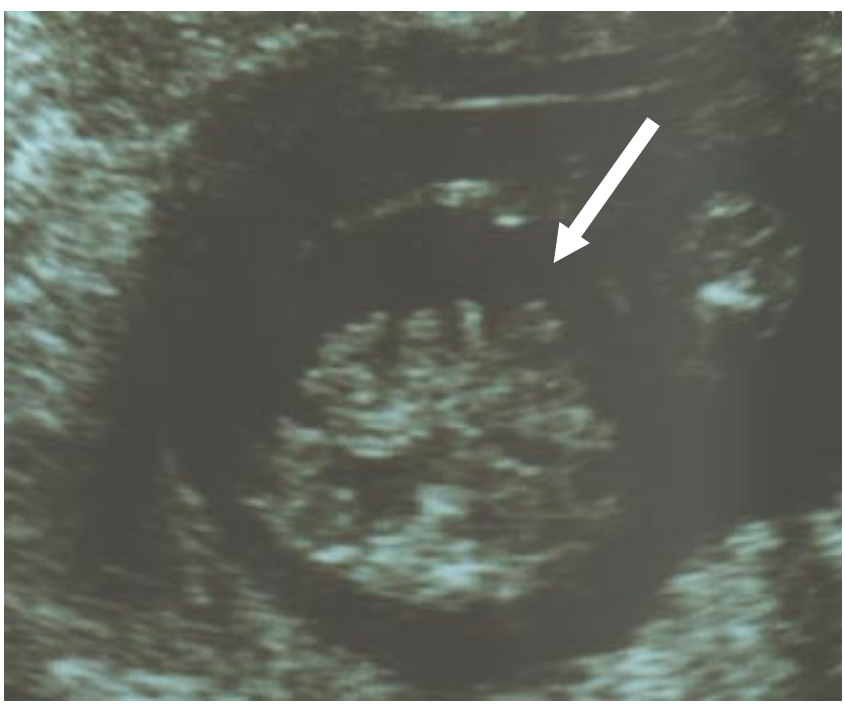

Figura 1 - Abdomen fetal com presença de ascite (seta)

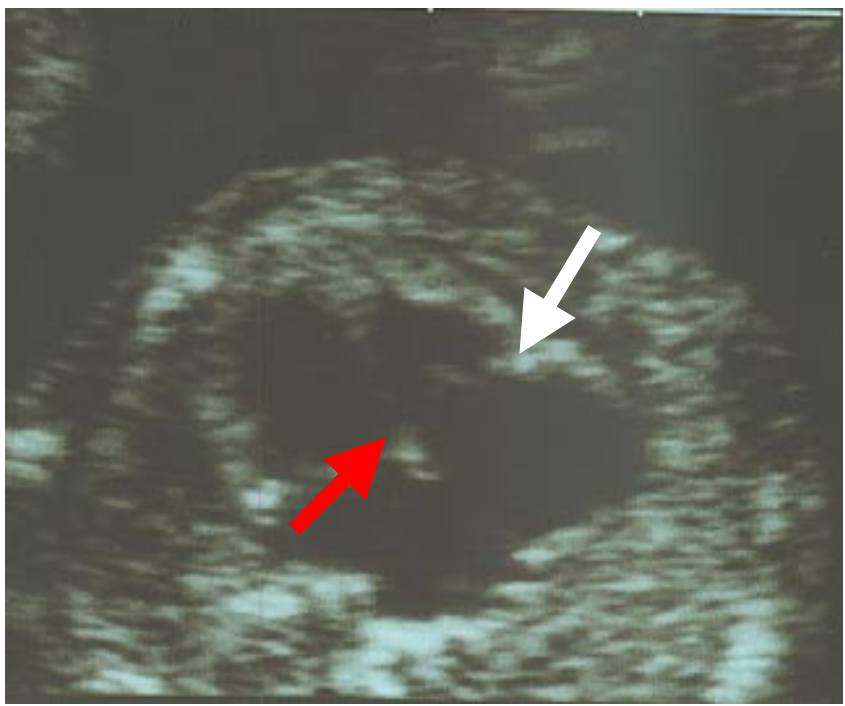

Figura 2 - Ultra-sonografia do coração fetal: câmaras cardíacas com dimensões no limite superior da normalidade (seta vermelha); derrame pericárdico.

Através de uma ecodopplercardiografia realizada na $20^{\mathrm{a}}$ semana, avaliou-se que o coração do feto estava normal do ponto de vista anatômico, sendo a insuficiência cardíaca secundária a alguma outra disfunção.

O quadro levou à suspeita de infecção congênita. Na tentativa de estabelecer a etiologia dos achados ultra-sonográficos, foi realizada cordocentese na $21^{\mathrm{a}}$ semana de gestação para obter: sorologia para toxoplasmose, citomegalovirus e parvovírus B19, dosagens de Gama-GT (gama glutamil transferase) e DHL (desidrogenase lática), hemograma e plaquetas. Uma nova ultrasonografia realizada durante a cordocentese já mostrava a regressão da ascite, bem como a normalidade da função cardíaca. Os resultados da análise do sangue fetal mostraram anemia (eritrócitos 2,2 milhões/ mm3 e hemoglobina 9,3 g/ dl), plaquetas 180.000/ mm3, DHL: $480 \mathrm{U} / \mathrm{L}$ (aumentada), Gama-GT: 27 U/L (aumentada), IgG reagente para Parvovírus B19 e IgM não reagente.

A sorologia materna para parvovirose indicava infecção pregressa e a pesquisa do DNA do parvovírus B19 através de PCR no soro materno revelou a presença do vírus.

Com estes resultados o casal optou por manter a gestação, sendo esta levada à termo, com o nascimento por parto cesárea de recém-nascido masculino pesando $2800 \mathrm{~g}$, com índice de Apgar 7 e 9 no $1^{\circ}$ e $5^{\circ}$ minutos. A criança tem mostrado desenvolvimento normal e não apresenta seqüelas da infecção pelo parvovírus B19.

\section{Discussão}

A ocorrência de parvovirose congênita é pouco freqüente e seu diagnóstico pré-natal ainda mais raro. Como a maioria das doenças infecciosas que podem comprometer a saúde do feto, a parvovirose B19 não é bem documentada, e também não está estabelecida a conduta a ser seguida pelo obstetra.

Três casos de infecção fetal pelo parvovírus B19 foram descritos ${ }^{3}$. Dois dos casos consistiam em fetos hidrópicos. O outro, resultou em morte intra-uterina. Existe evidência de que a infecção pelo parvovírus B19 pode provocar aborto espontâneo no $1^{\circ}$ trimestre, hidropisia fetal no segundo trimestre ou natimortalidade.

As parvoviroses têm um tropismo especial para células em divisão, principalmente as eritróides. A afinidade do parvovírus B19 por essas células progenitoras da medula é bem estabelecida, produzindo uma crise aplástica profunda, sendo a anemia resultante responsável por alterações cardíacas e edema. Embora a anemia hemolítica possa ser fatal, há casos descritos de sobrevivência sem seqüelas conhecidas ${ }^{3}$.

Este caso mostra a regressão espontânea de uma hidropisia fetal decorrente da infecção pelo parvovirus B19. Durante a cordocentese, o feto já apresentava regressão da ascite e restabelecimento da função cardíaca normal. Dado o bom prognóstico, a gestante optou por manter a gestação. O resultado dos diferentes exames realizados neste caso foi útil na determinação do diagnóstico. O nível sérico elevado das enzimas hepáticas Gama-GT e DHL é marcador indireto de infecção. O baixo índice de eritrócitos e hemoglobina, evidencia anemia do feto. Sabendose que o parvovírus possui um tropismo pelas células precursoras dos eritrócitos, este achado 
adquire importância. Os achados ultrasonográficos deste caso são bastante compativeis com o observado por outros autores. Um caso semelhante a este mostrou regressão espontânea da ascite fetal e diagnóstico pré-natal de parvovirose através de análise de sangue fetal ${ }^{5}$.

A presença IgM seria o marcador definitivo da infecção fetal, mas não houve detecção do anticorpo. Isto pode estar relacionado à época da realização da cordocentese, ocorrida durante a $21^{\text {a }}$ semana de gestação, quando não há maturidade imunológica fetal. Por ser capaz de transpor a barreira placentária, a IgG encontrada no sangue fetal era de provável origem materna. Como a sorologia materna indicava uma infecção não aguda, não havia, por este dado meios de se confirmar o diagnóstico da virose. A determinação da etiologia do quadro foi feita com a detecção do DNA viral no soro materno através de PCR.

Embora a hidropisia constitua um achado freqüente na anemia hemolítica fetal grave (eritroblastose fetal), sendo observada ainda em várias outras patologias infecciosas, ultimamente o encontro dessa anomalia tem constituído um importante achado clínico relacionado à infecção fetal pelo parvovírus B19. É estimado que $10 \%$ dos casos de hidropisia fetal aparentemente idiopática possam na verdade estar relacionadas à infecção fetal pelo parvovirus $\mathrm{B}_{19}{ }^{1}$, conferindo-lhe portanto importância prática em medicina fetal.

\section{ABSTRACT}

We report a case in which there was spontaneous regression of hydrops fetalis. Hydrops was probably caused by fetal infection with parvovirus B19. Anemia and hypokinesia of the heart were also observed. Diagnosis was accomplished by the ultrasound, virus detection in maternal serum, complete fetal blood count, and analysis of hepatic enzymes.

KEY WORDS: Parvovirus B19, prenatal diagnosis, non-immune hydrops fetalis, ultrasound, and infection during pregnancy

\section{Referências bibliográficas}

1. Anand A., Gray E. S., Brown T., Clewley J. P., Cohen B. J.: Human parvovirus infection in pregnancy and hidrops fetalis. N Engl J Med 1987; 316: 183-186.
2. Bittencourt A.L.: Infecções Congênitas Transplacentárias. Rio de Janeiro. Brasil. Revinter 1995.

3. Carrington D., Gilmore D.H., Whittle M.J., Gibson A.A.M., Brown T., Field A.M., Aitken D., Patrick W.J.A., Caul E.O, Clewley J.P.: Maternal serum alfa fetoprotein. A marker of fetal aplastic crisis during intrauterine human parvovirus infections. Lancet 1987; i: 433-435.

4. Cohen B.J., Hall S.M. Parvovirus B19 In: Greenough A, Osborn J, Sutherland S (eds.). Congenital, perinatal and neonatal infections. Churchil Livingstone, London, 1992; p. 157-170.

5. Faure J.M., Giacalone P.L., Deschamps F., Boulot P. Nonimmune hydrops fetalis caused by intrauterine human parvovirus B19 infection: a case of spontaneous reversal in utero. Fetal Diagn Ther 1997; 12: 66-67.

6. Nascimento J.P., Buckley M.M., Brown K.E., Cohen, B.J. The prevalence of antibody to human Parvovirus B19 in Rio de Janeiro, Brazil. Rev Inst Med trop São Paulo 1990; 32: 41-45.

7. Public Health Laboratory Service; Working Party on Fifth Disease. Prospective study of human parvovirus (B19) infection in pregnancy. Br Med J 1990; 300: 1166-1170.

8. Tratschin J.D., Siegl G.: Clinical manifestation and laboratory diagnosis of human Parvovirus B19 infection. Biotest Bull 1990; 4: 147-152. 